LAWRENCE LIVERMORE N A T IO N A L LABORATORY

\section{Status of Safety and Environmental Activities in the US Fusion Program}

D. A. Petti, S. Reyes, L. C. Cadwallader, J. F. Latkowski

September 4, 2004

16th ANS Technology of Fusion Energy (TOFE) Madison, WI, United States

September 14, 2004 through September 16, 2004 
This document was prepared as an account of work sponsored by an agency of the United States Government. Neither the United States Government nor the University of California nor any of their employees, makes any warranty, express or implied, or assumes any legal liability or responsibility for the accuracy, completeness, or usefulness of any information, apparatus, product, or process disclosed, or represents that its use would not infringe privately owned rights. Reference herein to any specific commercial product, process, or service by trade name, trademark, manufacturer, or otherwise, does not necessarily constitute or imply its endorsement, recommendation, or favoring by the United States Government or the University of California. The views and opinions of authors expressed herein do not necessarily state or reflect those of the United States Government or the University of California, and shall not be used for advertising or product endorsement purposes. 


\title{
Status of Safety and Environmental Activities in the US Fusion Program
}

\author{
D. A. Petti, ${ }^{a}$ S. Reyes, ${ }^{b}$ L. C. Cadwallader, ${ }^{a}$ and J. F. Latkowski ${ }^{b}$ \\ a) Idaho National Engineering and Environmental Laboratory,PO Box 1625, Idaho Falls, ID 83415, pti@inel.gov \\ b) Lawrence Livermore National Laboratory, PO Box 808, Livermore, CA 94551
}

This paper presents an overview of recent safety efforts in both magnetic and inertial fusion energy. Safety has been a part of fusion design and operations since the inception of fusion research. Safety research and safety design support have been provided for a variety of experiments in both the magnetic and inertial fusion programs. The main safety issues are reviewed, some recent safety highlights are discussed and the programmatic impacts that safety research has had are presented. Future directions in the safety and environmental area are proposed.

\section{INTRODUCTION}

The safety and environmental (S\&E) advantages of fusion have been recognized since the earliest days of the US fusion program. Over the past 25 years, the magnetic fusion energy (MFE) Fusion Safety Program (FSP) at the Idaho National Engineering and Environmental Laboratory (INEEL) and the inertial fusion energy (IFE) safety group of the Fusion Energy Program (FEP) at Lawrence Livermore National Laboratory (LLNL) have been conducting safety research and development (R\&D) and $\mathrm{S} \& \mathrm{E}$ assessments of conceptual designs to demonstrate the S\&E potential of fusion.

S\&E research is focused on understanding the behavior of the largest sources of radioactive and hazardous materials in a fusion facility, understanding how energy sources in a fusion facility could mobilize those materials, developing integrated state of the art S\&E computer codes and risk tools for safety assessment, and evaluating $\mathrm{S} \& \mathrm{E}$ issues associated with emerging design concepts in the fusion community. Our evaluations of S\&E issues associated with emerging IFE design concepts include support to the High Average Power Laser (HAPL) program to advance the science and technology for a drywall, laser-driven IFE power plant, and collaboration with the Heavy Ion Fusion (HIF) and Z-Pinch programs for the development of alternative, thick-liquid-wall IFE concepts. Recent S\&E support to MFE design concepts includes the Advanced Power Extraction (APEX) and Advanced Reactor Innovations and Evaluation Study (ARIES), and burning plasma experiment designs, including preliminary studies of the Fusion Ignition Research Experiment (FIRE) and detailed safety analyses for the International Thermonuclear Experimental Reactor (ITER).

Excellent progress has been made in understanding the nature of the S\&E concerns associated with magnetic and inertial fusion. This paper presents key R\&D highlights over the past 15 years, reviews recent safety assessment results for both MFE (e.g., APEX, ARIES, FIRE, ITER) and IFE (e.g., HYLIFE-II, SOMBRERO) designs, and discusses impact of the results on future programmatic directions in the fusion program.

\section{SOURCE TERM HAZARD CHARACTERIZATION}

Safety assessment generally begins with the determination of what hazards are present in a given design. As fusion moves towards machines using tritium fuel and to high power levels, the hazards increase commensurately. Several types of hazards are common in MFE and IFE experiments and power plant designs.

\section{II.A Radiological Hazards}

There are a number of radiological hazards in fusion experiments. ${ }^{1,2}$ The radiological release hazards dominate the off-site consequences for the majority of accident events in fusion. Some of the principal radiological hazards in fusion are given in Table I.

\section{II.B Chemical Hazards}

There has been a growing realization in the fusion safety community over the past few years that some fusion designs host fairly large inventories of chemically hazardous materials. ${ }^{3}$ While radiological concerns continue to dominate the public and worker risk, there are still important safety concerns with potential chemical releases. Another concern about chemicals is that allowable public exposure concentrations have become more strict in the past two decades, much more so than radiation exposure limits. In some cases, the restrictive 
TABLE I. Fusion Experiment Radiological Hazards

\begin{tabular}{|l|l|}
\hline \multicolumn{1}{|c|}{ Specie } & \multicolumn{1}{|c|}{ Potential Constituents } \\
\hline Fuel & $\begin{array}{l}\text { Tritium is naturally } \\
\text { radioactive. Hohlraums can } \\
\text { also have activated } \\
\text { hydrocarbons and metals. }\end{array}$ \\
\hline Activated Structural & $\begin{array}{l}\text { Vessel wall (Fe, Cr) and } \\
\text { blanket materials can become } \\
\text { neutron-activated }\end{array}$ \\
\hline Activated dust & $\begin{array}{l}\text { Erosion dust from plasma } \\
\text { facing components (PFCs; } \\
\text { Be, C, W), diagnostic devices } \\
\text { (Cu), antennas (Cu), and } \\
\text { other materials can be } \\
\text { tritiated and activated }\end{array}$ \\
\hline Activated coolants and & $\begin{array}{l}\text { Some coolants (H }{ }_{2} \text { O, Flibe, } \\
\text { Li, LiPb) and/or their } \\
\text { impurities can become } \\
\text { activated. Some gaseous } \\
\text { coolants can also become } \\
\text { activated. Vacuum pump oils } \\
\text { can become tritiated and } \\
\text { contaminated with dust. }\end{array}$ \\
\hline Activated gases & $\begin{array}{l}\text { Air, sulfur hexafluoride, and } \\
\text { nitrogen in MFE and IFE; } \\
\text { some IFE designs can also } \\
\text { have xenon and fluorine. }\end{array}$ \\
\hline
\end{tabular}

limits for chemical exposure have resulted in chemical exposures being as consequential as radiological exposures. ${ }^{4,5}$ The chemical hazards include use of invessel beryllium and other less toxic materials, such as tungsten, copper, and carbon; these dusts pose varying health threats. An IFE design may have all of these material concerns and the added concerns of hohlraum material debris in the reaction chamber. IFE also has the concerns of target manufacture, where dusts can be created, potentially containing lead, beryllium, mercury, or other materials.

\section{ENERGY SOURCE EVALUATIONS}

The energy sources that can breach confinement boundaries or otherwise mobilize hazardous materials must also be understood and characterized in normal operation and off-normal events to gain a complete, accurate, and balanced safety profile for the facility.

- Chemical energy. An important energy source in fusion facilities is oxidation of heated fusion materials with air or steam. INEEL tests have shown that after materials oxidize, the oxides tend to volatilize and form aerosols which are easily mobilized by flowing gas. ${ }^{6,7}$ Both MFE and IFE designs have required safety calculations for material oxidation, including carbon-fiber composite tiles that can release absorbed elemental tritium when oxidized. We also note that beryllium compounds, such as $\mathrm{BeO}$, are carcinogenic like the elemental metal. Dust generated in experiments is also chemically reactive.

-Electrical energy. The stored electrical energy in superconducting magnets is a large energy source for MFE. MFE magnet faults have been postulated to lead to electrical arcs that can damage confinement barriers such as the vacuum vessel or the cryostat. Some IFE designs using particle beams for fuel compression and heating may have stored electrical energy in the beam and steering magnets, but not nearly the magnitude as found in MFE.

-Thermal energy. Without proper cooling, the thermal energy in the structures of a fusion experiment due to activation product decay heating, plasma heat generation and the heat from plasma heating systems can result in mobilization of the activated material in the structures.

-Pressure energy. Pressurized coolants and compressed gases are used in both MFE and IFE designs. Coolants may change phase when released and can threaten the confinement boundaries. Both IFE and MFE experiments have large vacuum reservoirs that can suffer a breach; perhaps a port window failure, a valve leak, etc. IFE also has the safety issue of compressing tritium gas to high pressure to fill target pellets.

-Radiation energy. Ionizing radiation from tritium fuel and from neutron activated materials pose worker, public, and environmental hazards. Non-ionizing radiation also poses hazards. In IFE, lasers can be used to ignite the fuel, using very high energy pulses for short times. MFE may use lasers for diagnostics. The laser energy is much less than for IFE, but can be sufficient energy to raise micron size dust to ignition temperature in air.

\section{SAFETY ASSESSMENT TOOL DEVELOPMENT}

A number of experiments have been performed and a variety of tools have been developed to characterize the hazardous materials and the energies that can mobilize them. The experiments have focused on the safety of materials, including chemical reactivity of fusion materials, tritium uptake and release from plasma facing components (PFCs), and release, volatilization, and mobilization from oxidized fusion structural materials. Table II lists the materials that have been tested at the INEEL over the past decade for high temperature exposure to steam from coolant and ingress air. These data have been incorporated into accident analyses to estimate the amounts of radiological and toxicological that could occur in postulated accident scenarios. 
TABLE II. Material Safety Tests Performed by the INEEL Fusion Safety Program

\begin{tabular}{|c|c|c|c|c|}
\hline Material & Environment & $\begin{array}{l}\text { Oxidation temperature } \\
\text { range } \\
\text { (C) }\end{array}$ & $\begin{array}{c}\text { Mobilization } \\
\text { measurements } \\
\text { performed }\end{array}$ & $\begin{array}{c}\text { Ion implantation tests } \\
\text { performed }\end{array}$ \\
\hline \multicolumn{5}{|c|}{ Steels } \\
\hline $\begin{array}{l}\text { PCA steel, } \\
\text { solid disk }\end{array}$ & air, steam & $700-1200$ & yes & yes \\
\hline $\begin{array}{l}\text { Austenitic stainless steel, } \\
\text { solid disk }\end{array}$ & air, steam & $800-1200$ & yes & \\
\hline $\begin{array}{l}\text { Ferritic steel } \\
\text { HT-9, solid disk }\end{array}$ & air, steam & $600-1200$ & yes & yes \\
\hline \multicolumn{5}{|c|}{ Refractories } \\
\hline $\begin{array}{l}\text { Niobium alloy, } \\
\text { solid disk }\end{array}$ & air, steam & $800-1200$ & yes & \\
\hline $\begin{array}{l}\text { Tantalum, } \\
\text { solid disk }\end{array}$ & air & $500-1200$ & & \\
\hline $\begin{array}{l}\text { Molybdenum TZM alloy, } \\
\text { solid disk }\end{array}$ & air & $400-800$ & yes & \\
\hline Tungsten foil & & & & yes \\
\hline $\begin{array}{l}\text { Tungsten alloy, solid } \\
\text { disk }\end{array}$ & air, steam & $600-1200$ & yes & \\
\hline $\begin{array}{l}\text { Tungsten, plasma } \\
\text { sprayed disk }\end{array}$ & steam & $800-1200$ & yes & yes \\
\hline $\begin{array}{l}\text { Tungsten brush, } \\
\text { 3.2-mm diameter rods }\end{array}$ & steam & $500-1100$ & yes & \\
\hline Tungsten carbide, disk & & & & yes \\
\hline $\begin{array}{l}\text { Vanadium alloy } \\
\text { V-15Cr-5Ti, solid disk }\end{array}$ & air & $600-1200$ & yes & yes \\
\hline \multicolumn{5}{|c|}{ Beryllium } \\
\hline $\begin{array}{l}\text { Beryllium, } \\
0.2-\text { and 2-mm diameter } \\
\text { pebbles }\end{array}$ & steam & $350-900$ & & \\
\hline $\begin{array}{l}\text { Beryllium, } 14 \text { to } \\
31 \text { micron powder }\end{array}$ & steam & $300-500$ & & \\
\hline $\begin{array}{l}\text { Beryllium, } \\
\text { solid rods }\end{array}$ & steam & $400-600$ & yes & \\
\hline $\begin{array}{l}\text { Beryllium, } \\
\text { plasma sprayed }\end{array}$ & steam & $400-600$ & yes & \\
\hline $\begin{array}{l}\text { Beryllium, } \\
88 \% \text { dense disk }\end{array}$ & steam & $400-600$ & yes & \\
\hline $\begin{array}{l}\text { Irradiated beryllium, } \\
\text { solid rods }\end{array}$ & steam & $400-700$ & yes & \\
\hline $\begin{array}{l}\text { Carbon-coated beryllium } \\
\text { foil }\end{array}$ & & & & yes \\
\hline \multicolumn{5}{|c|}{ Graphites } \\
\hline $\begin{array}{l}\text { Graphite, } \\
\text { solid disk }\end{array}$ & steam & $1000-1700$ & & \\
\hline $\begin{array}{l}\text { Graphite, } \\
\text { solid disk }\end{array}$ & air & $800-1800$ & & \\
\hline $\begin{array}{l}\text { Carbon fiber composite, } \\
\text { solid disk }\end{array}$ & air & $525-1000$ & yes & \\
\hline Amorphous carbon film & & & & yes \\
\hline \multicolumn{5}{|c|}{ Copper alloys } \\
\hline Copper alloy, solid disk & air, steam & $600-1200$ & yes & \\
\hline CuCrZr alloy & & & & yes \\
\hline $\mathrm{Cu}-\mathrm{OFHC}$ disk & & & & yes \\
\hline $\mathrm{Cu} / \mathrm{Be}$ disk & & & & yes \\
\hline W-coated copper disk & & & & yes \\
\hline
\end{tabular}


In recent years as fusion designs have evolved to contain greater detail, the US Fusion Program has dedicated greater resources to the development and implementation of state-of-the-art methodologies for S\&E analyses. In some cases, this required improving or upgrading similar fission safety codes for fusion conditions. In other cases, it required development of fusion-specific codes. The set of tools for IFE has been described in detail ${ }^{8}$ and currently includes neutron transport and activation calculations, heat transfer, thermal-hydraulics and aerosol transport simulations, and finally, accident consequence analysis and radiological/toxicological dose evaluation. MFE and IFE tools are very similar.

IFE radionuclide inventories are calculated using particle transport and activation methodologies. Fusion safety analyses typically use Monte Carlo codes, such as TART, ${ }^{9}$ to calculate the neutron and/or photon transport within the power plant components. TART has traditionally been used by the LLNL FEP to develop detailed 3-D neutronics models such as that shown in Figure 1. The Monte Carlo method is applied to determine energy-dependent particle path-lengths in the regions of interest. The activation code $\mathrm{ACAB}^{10}$ can use 3-D neutron fluxes generated by Monte Carlo neutron transport codes such as TART, allowing for inventory calculation within complex geometries. The code has the ability to simulate realistic operational scenarios of very different nuclear systems. It can provide a very accurate and efficient modeling of the pulsed schedule for inertial fusion experimental facilities, such as the National Ignition Facility (NIF). The MFE safety program relies on neutronics work by the University of WisconsinMadison researchers to support safety and waste disposal analyses for design activities. An example is the work done for the Fusion Ignition Research Experiment (FIRE). ${ }^{11}$ The MFE approach is to use the MCNP code or the ONEDANT particle transport module in DANTSYS, and activation analysis is performed using the DKRPULSAR code or, more recently, the ALARA pulsed activation code. The FENDL-2 nuclear evaluated data set is used in both cases.

Oxidation-driven mobilization experiments outlined in Table II have produced data that has allowed better estimation of radionuclide release fractions during accident conditions. These data have been used with the heat transfer capability of the CHEMCON $\operatorname{code}^{12}$ to obtain radioactivity source terms during accident scenarios in both IFE and MFE. CHEMCON was developed by the INEEL FSP to analyze thermal transients and has been updated to account for new experimental data and a more realistic oxidation package. ${ }^{8}$ Once the radioactive source term is known, the MELCOR thermal-hydraulics code ${ }^{13}$ is used to simulate a wide range of physical phenomena including heat transfer, dust and aerosol physics, and fusion product release and transport. MELCOR was originally developed at Sandia National Laboratories (SNL) to treat severe accident phenomena in boiling and pressurized fission reactors. Since 1995, the INEEL has performed a continuous development effort to adapt MELCOR to fusion safety studies. ${ }^{14}$

MFE S\&E uses a code for predicting electric arc damage from the unmitigated quench of a superconducting magnet. The code is called MAGARC and it uses 3-D heat conduction equations and a resistive circuit network to account for the arcing, bypass currents, magnet melting, and heat conduction. ${ }^{15}$ Another code of importance in both MFE and IFE safety is the TMAP code that calculates tritium migration through materials such as in-vessel cooling tube walls and heat exchanger tubes. The most recent version of TMAP has been validated and verified. ${ }^{16}$

Finally, radiological dose conversion factors (DCFs) are used to translate the activity levels present in the environment (obtained from MELCOR) to an equivalent dose to humans. As a result of the collaboration between the LLNL FEP and our international colleagues in UNED/Instituto de Fusion Nuclear, in Madrid, Spain, the traditional fission DCF libraries have been expanded to include specific IFE radionuclides relevant for fusion ${ }^{17}$ and these updated libraries have been used for a realistic assessment of radiological doses. The INEEL FSP researchers collaborated with SNL in the early 1990's to upgrade the MACCS computer code. MFE developed a food chain model ${ }^{18}$ for use in MACCS2, and the MACCS developers included all DOE DCFs in MACCS2. ${ }^{19}$ Use of the codes described above allows for calculation of accident consequences and evaluation of radioactive safety hazards from a fusion power plant. As mentioned previously, chemical hazards must also be considered to provide a complete safety assessment for fusion power plants. Fusion safety researchers have included chemical toxicity assessments as part of the overall safety analyses, using atmospheric dispersion simulations to estimate the time-averaged peak concentrations resulting from accidental releases. ${ }^{4,20}$

Parallel to the traditional deterministic safety analysis approach described above, MFE and IFE safety researchers have also developed methodologies for probabilistic safety assessment (PSA) of fusion facilities. The traditional, deterministic safety analysis approach is important for bounding the worst consequences for facility acceptance and emergency planning. However, PSA treats small consequence events that have a reasonably high likelihood of occurrence, and therefore require attention by designers because such events must be appropriately mitigated to demonstrate good control 
and stewardship of a facility. A variety of PSA initiating event identification techniques have been used thus far in both MFE and IFE fusion designs. ${ }^{21,22}$

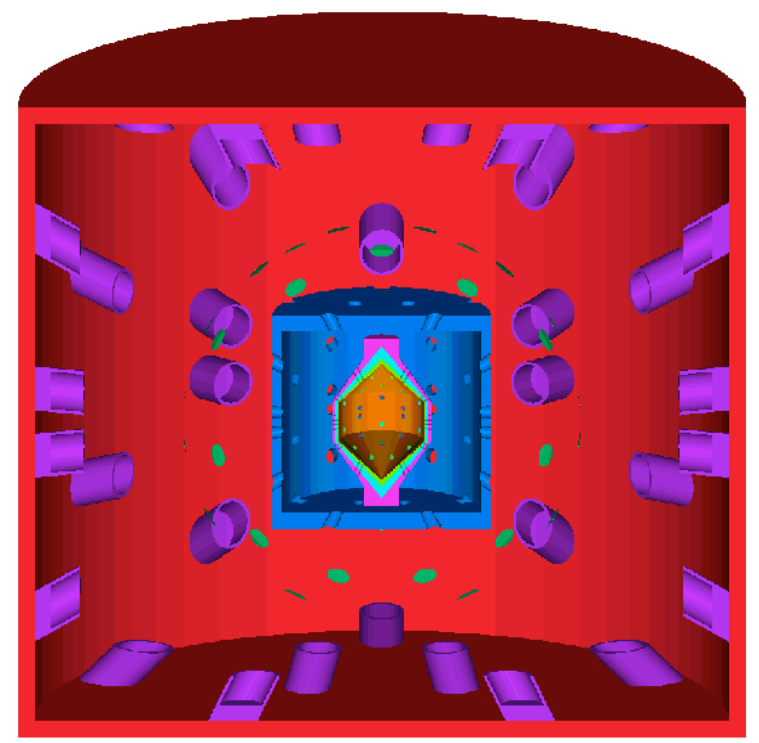

Figure 1. Cross section of the TART computer model for the SOMBRERO IFE power plant design. ${ }^{23}$

\section{RECENT S\&E EVALUATIONS AND FINDINGS}

MFE safety assessment work was recently performed for the Fusion Ignition Research Experiment (FIRE). In the FIRE design activity, safety researchers noted that the DOE had published some emergency evacuation guidance after the fusion safety standard. The fusion safety standards $\mathrm{s}^{24,25}$ directed using the then-current practice of using best estimate radiological dispersion calculations to give a realistic estimate of the radiological dose for probabilistic safety assessment. Then, DOE emergency planning guidance was published that directed usage of conservative weather conditions to define the largest area that would require evacuation due to a large release event. Therefore, to meet the DOE emergency planning guidance and avoid the need for an evacuation plan, conservative weather calculations must be used and the results must show that off-site doses are small. This interpretation of the DOE emergency management guidance caused a safety limit of $13 \mathrm{~g}$ of releasable tritium to be placed on FIRE systems. ${ }^{26}$

Another important safety result was the erosion damage expected from Edge Localized Modes (ELMs) in advanced tokamak operation. The ELMs posed a serious divertor material erosion threat due to the rapid pulsed heating bursts on the tungsten divertor surface. There are few data in the literature about tungsten dust explosibility, but in general the smaller the dust size, the more energetic the deflagration event, and the tungsten dust produced is expected to be small like other tokamak dusts, $<10$ microns. ${ }^{27}$ This ELM issue is being addressed by operating machines to learn how to recognize inception of an ELM and how to control ELMs to reduce divertor damage, such as sweeping the ELM bursts to diffuse the heating. ${ }^{28}$

In the past few years IFE safety researchers have completed safety assessments for two IFE power plant designs and an IFE target fabrication facility. ${ }^{23,29-31}$ The results from these analyses show that the dominant dose comes from the tritium in HTO form. Assuming typical weather conditions, total off-site doses below the $10-\mathrm{mSv}$ evaluation guideline established by the DOE Fusion Safety Standards ${ }^{24,25}$ seem to be achievable. It has been found that if conservative weather conditions were used in calculations, the off-site doses would result in an order of magnitude higher dose. In that case, design changes and further analysis would be needed to meet the safety requirements. In the case of an accident in the target fabrication facility, the total plant tritium inventory is not an issue, only the segmented portion of the inventory that is vulnerable to release is important. If designs for target fabrication facilities can ensure that canisters/fill rooms remain isolated from each other during an accident, then this segmentation will help meet the safety goals. ${ }^{31}$

The APEX study has proposed molten salt-cooled solid wall and liquid wall MFE fusion designs. An analysis was recently completed for two of these designs, a Flibe cooled solid first wall and a Flinabe cooled liquid first wall design. Both designs used ferritic steel as the structural material. ${ }^{5}$ The results for loss of coolant accidents showed that the peak blanket temperatures remained below values where structural integrity would be lost, provided that natural convection in the vacuum vessel cooling system was initiated. An interesting result was that the Flinabe liquid wall design experienced high temperatures in a loss of flow scenario; because of the decay of Na-22 and Na-24 within the coolant itself. A passive drain tank was proposed to gravity flow the Flinabe away from the blanket in loss of flow situations.

Chemical toxicity assessments were conducted for two candidate IFE target materials $(\mathrm{Hg}$ and $\mathrm{Pb})$ and for the beryllium present in the molten salt Flibe. ${ }^{4,20}$ For these materials it was found that the chemical toxicity was the dominant public safety concern. Results from these studies show that it is crucial to address chemical hazards for a complete safety assessment for fusion power plants.

A Monte Carlo uncertainty analysis procedure for activation calculations has been developed based on simultaneous random sampling of all the cross sections involved in a problem, and it has been implemented in the 
activation code ACAB. ${ }^{32}$ This work has been performed in collaboration with UNED/Instituto de Fusion Nuclear in Madrid, Spain. Using the procedure, it is possible to propagate activation cross section uncertainties forward to provide uncertainties on the overall radionuclide activities and any activity-based radiological results. Ultimately, this capability will be used to identify nuclear reactions that are both important to the desired results and have relatively large uncertainties. It is hoped that this will help drive experiments to perform more precise measurements of critical activation cross sections.

Regarding environmental studies, previous work has traditionally used the waste disposal ratings (WDRs) as defined in 10CFR61 as a waste disposal index in order to determine if a particular component qualifies for shallow land burial disposal. However, this may not be the best waste management option if one has to dispose of relatively large volumes. The IAEA has proposed concentration levels of radionuclides in solid materials below which the materials may be released on the grounds that the associated radiation hazards are trivial. ${ }^{33}$ Some recent MFE work in low activation materials (LAMs) has determined that a combined strategy is needed to attain the goal of no high level waste for fusion. Analysis has shown that a combined strategy of specific LAM usage and shielding allows the outboard fusion vacuum vessel and all magnets to be cleared or recycled, and also that adequate shielding allows the activated material that cannot be cleared to be disposed of as low

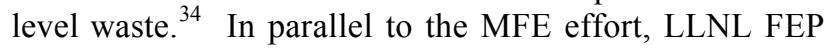
personnel have implemented the concept of Clearance Indexes in the activation code $\mathrm{ACAB}$ in order to determine if components of a fusion energy power plant could be cleared or relinquished from regulatory control. Waste management studies for the HYLIFE-II IFE design show that in the case of the confinement building, which dominates the total volume of the waste stream, clearance would be possible after about one year of cooling following the shutdown of the plant.

\section{PROGRAMMATIC IMPACTS OF SAFETY}

The US Fusion Safety Program activities have has impact in diverse domestic and international MFE and IFE projects.

Within the scope of the ARIES program, safety personnel have traditionally been involved in the ARIES team for design studies of fusion energy by providing input on design windows for IFE concepts. IFE designs have also benefited from $\mathrm{S} \& \mathrm{E}$ findings from the recent ARIES-IFE study, such as the updated assessment of the choice of chamber structural material for a liquid wall chamber concept. ${ }^{35}$ In addition to the original choice of stainless steel 304, other alternate materials were considered. Since then, the activation behaviour of the different steels considered in ARIES has been explored in order to determine if they are acceptable options from a waste management perspective. These S\&E studies have shown that although SS 304 shows an excellent low activation performance, oxide-dispersion-strengthened (ODS) ferritic steel could be a more promising option given the potential for high temperature operation. ${ }^{35,36}$

The High Average Power Lasers (HAPL) Program currently leads laser facility studies for inertial fusion energy. Since the beginning of the program's activities we have provided expert input in the areas of S\&E and $\mathrm{x}$ ray radiation damage for first wall and optic materials. ${ }^{37}$ Chamber material selection for laser IFE has taken into account safety results from the SOMBRERO design accident assessment. ${ }^{23}$ Recent oxidation data of carbon fiber composite structures ${ }^{38}$ has been studied within the scope of the HAPL program and S\&E guidance has also been provided for alternative first wall candidates such as tungsten and ferritic steel.

The LLNL's FEP S\&E personnel have traditionally been largely involved with the National Ignition Facility (NIF) neutronics effort. The main goal of that group is the assessment of activation issues such as NIF radiation doses to workers and components. In particular, the expertise developed for IFE neutronics has been very synergistic with the need for detailed 3-D models for NIF. The effort in this area has supported the NIF Final Safety Analysis Report as well as the Environmental Impact Statement.

US ITER Test Blanket Module (TBM) group is responsible for designing potential candidate breeding blanket modules that the participants may place in ITER testing ports. Ongoing work by INEEL/LLNL fusion safety experts is providing safety assessments for the ITER TBM design options. Work developed to-date in this area consists of heat transport calculations with the computer code CHEMCON in order to simulate temperature excursions in first wall and blanket components during loss-of-flow and loss-of-cooling accident scenarios. Future work will involve complete safety assessments including MELCOR models for the TBM and ancillary systems.

\section{FUTURE DIRECTIONS}

Over the past 15 years, safety analyses for MFE systems, especially ITER, have matured significantly. The behavior of the tokamak system with respect to public safety is better understood than ever before. Uncertainties still remain but they have been identified and research is in place to reduce them to the extent practical. Much of the future work for ITER is to support 
regulatory approval. ${ }^{39}$ Code development, and code verification and validation work must be performed to support ITER regulatory approval because these code results are used to assure public safety. In addition, validation of the safety limits that have been placed on erosion dust created from, and tritium uptake in, the $\mathrm{W}, \mathrm{C}$, and Be plasma facing materials used in ITER is required. It is anticipated that further $R \& D$ can help validate these safety limits but only ITER operations will yield answers to dust generation and tritium uptake definitive enough to convince regulators. Furthermore, regulators will likely use a graduated licensing approach, such as was used at JET for the preliminary tritium experiment and the deuterium tritium experiment campaigns. ${ }^{40}$ Licensing ITER for each operating stage will help regulators to gain confidence in the behavior of the facility, and the operating experience results from each stage will provide data useful to benchmark the safety limits and assumptions for the following stage. The US fusion safety program will also support the US design effort on potential ITER TBMs.

Some fusion facilities, such as JET and TFTR, ${ }^{40,41}$ have made good use of probabilistic safety assessment in making their cases for licensing tritium usage, and ITER has also combined the traditional deterministic or 'worst case' safety analysis with probabilistic methods to provide a complete spectrum of potential accident scenarios. Ultimately how ITER is sited and what safety approaches are used to document public safety will set a precedent for the future regulatory approach and framework for tokamaks and other fusion facilities.

Beyond public radiological safety, continued cognizance of chemical safety issues and how chemical safety is approached in the DOE, particularly for remediation workers and the public, and waste management is important to ensure that fusion designs can respond appropriately to changes in regulations in this area. Of particular importance for fusion given its size is how the DOE site wastes are remediated and what if any changes occur to the definition of low level waste and in particular the definition of clearance of materials for recycling back into processes or for free release. In much of the previous work for both magnetic and inertial fusion studies, a great deal of effort has been expended in an attempt to avoid the generation of high-level waste. Relatively little effort has gone into reducing the overall waste stream. It is not clear that the public understands or appreciates the differences between low level waste that meets 10CFR61.55 Class C requirements versus high level waste that exceeds these requirements. ${ }^{34,42}$ As a result, the choice between generation of small quantities of high-level waste versus large quantities of low-level waste is a difficult one worthy of community discussion and debate. This discussion must include issues such as clearance, recycling/reuse, and disposal.

Both MFE and IFE safety requires further examination of occupational safety, not merely radiological safety but all aspects of safety in operating and maintaining the experiments. Occupational safety requires the level of design detail found in NIF, ITER, or existing experiments such as JET, to support identification of the hazards that workers are exposed to in facility rooms and areas. Once again, the operating experiences from such machines will provide valuable data on occupational safety. Such information will allow identification of the most important or sensitive issues for worker safety.

From the IFE safety perspective, more work is recommended on estimation of accidental releases and occupational exposures to assess realistic air concentrations for the workers and the public. More sophisticated models for accident analyses should account for chemical reactivity with other compounds existing in experiment, power plant, and target fabrication facility atmospheres. Implementation of safety features, such as segregation of inventories and additional levels of confinement, are essential to minimize potential radioactive and chemical exposures. Because micron scale dust is created and can accumulate in regions of vessels where it can easily be mobilized, the dust must be studied for its mobilization and hazards. ${ }^{43}$ IFE researchers plan to continue studying potential coolant/chamber/target materials in order to optimize the S\&E characteristics of fusion power plant designs. Safety codes will be updated as needed to account for new materials, and code libraries will be expanded accordingly to account for updated mobilization and/or radiological data. Cross section uncertainty analyses will be used to identify nuclear reactions that significantly contribute to uncertainty of activation results in a fusion environment. These studies will help drive experiments for a more accurate estimation of critical reaction cross sections.

The US fusion safety program is also very active in the International Energy Agency's (IEA's) Implementing Agreement on the Economic, Safety, and Environmental Aspects of Fusion Power. US safety personnel are active in almost all of the eight task areas, including tritium and activation product source terms, thermofluid modeling, component failure rates, radioactive waste studies, socioeconomic studies, magnet safety studies, and power plant design studies. The future holds more fruitful collaborations with IEA participants. The US fusion safety program is also active in the International Atomic Energy Agency's (IAEA's) technical meetings on fusion safety, where safety professionals meet every few years to present progress and exchange ideas. 


\section{ACKNOWLEDGMENTS}

This work was prepared for the US Department of Energy, Office of Fusion Energy Sciences, under the DOE Idaho Field Office contract number DE-AC0799ID13727 and the University of California, Lawrence Livermore National Laboratory contract number W-7405Eng-48.

\section{REFERENCES}

1. J. RAEDER, Controlled Nuclear Fusion: Fundamentals of Its Utilization for Energy Supply, John Wiley \& Sons, New York (1986).

2. Energy from Inertial Fusion, International Atomic Energy Agency, Vienna, chapter 6 (1995).

3. L. CADWALLADER, "Chemical Hazards and Safety Issues in Fusion Safety Design," Fusion Science and Technology, 44, 369 (2003).

4. S. REYES et al., "Safety Issues of $\mathrm{Hg}$ and $\mathrm{Pb}$ as IFE Target Materials: Radiological versus Chemical Toxicity," Fusion Science and Technology, 44, 400 (2003).

5. B. J. MERRILL et al., "Safety Assessment of APEX Advanced Ferritic Steel Molten Salt Blanket Design Concepts," Fusion Engineering and Design, in press.

6. G. R. SMOLIK, K. A. McCARTHY, V. L. SMITHWACKERLE, "Characterization of Oxide Breakup by Convective Currents," Proceedings of the $15^{\text {th }}$ Symposium on Fusion Engineering, October 11-15, 1993, Hyannis, MA, IEEE, 923 (1993).

7. D. L. HAGRMAN, G. R. SMOLIK, K. A. McCARTHY, and D. A. PETTI, "Volatilization from PCA Steel Alloy," Fusion Technology, 30, 1442 (1996).

8. S. REYES, J. F. LATKOWSKI, J. SANZ, J. GOMEZ DEL RIO, "Safety Assessment for Inertial Fusion Energy Power Plants: Methodology and Application to the Analysis of the HYLIFE-II and SOMBRERO Conceptual Designs, " Journal of Fusion Energy, 20 (1), 23 (2001).

9. D. E. CULLEN, Users Manual for TART2002: A Coupled Neutron-Photon, 3-D, Combinatorial Geometry, Time Dependent, Monte Carlo Transport Code, UCRL-ID-126455, Rev. 4, Lawrence Livermore National Laboratory (2003).

10. J. SANZ, ACAB98: Activation Code for Fusion Applications. User's Manual V4.0, UCRL-CR133040, Universidad Nacional de Educacion a Distancia (UNED) and Lawrence Livermore National Laboratory, (1999).

11. M. E. SAWAN, H. Y. KHATER, S. J. ZINKLE, "Nuclear Features of the Fusion Ignition Research Experiment (FIRE)," Fusion Engineering and Design, 63-64, 547 (2002).
12. M. J. GAETA, B. J. MERRILL, CHEMCON User's Manual Version 3.1, INEL-95/0147, Idaho National Engineering and Environmental Laboratory (1995).

13. R. O. GAUNTT, R. K. COLE, S. A. HODGE, S. B. RODRIGUEZ, R. L. SANDERS, R. C. SMITH, D. S. STUART, R. M. SUMMERS, M. F. YOUNG, MELCOR Computer Code Manuals, NUREG/CR6119, Vol. 1, Rev. 1, SAND97-2398, US Nuclear Regulatory Commission (1997).

14. B. J. MERRILL, R. L. MOORE, S. T. POLKINGHORNE, and D. A. PETTI, "Modifications to the MELCOR Code for Application in Fusion Accident Analyses," Fusion Engineering and Design, 51-52, 555 (2000).

15. B. J. MERRILL, "Modeling and Unmitigated Quench Event in an ITER Toroidal Field Magnet," Fusion Technology, 37, 231 (2000).

16. G. R. LONGHURST and J. AMBROSEK, "Verification and Validation of TMAP7," to be presented at the $7^{\text {th }}$ International Conference on Tritium Science and Technology, Baden-Baden, Germany, 12-17 September, 2004.

17. J. GOMEZ DEL RIO, J. SANZ, S. REYES, J. F. LATKOWSKI, "Parametric Study of Accident Consequences from Different Weather Conditions. Application to IFE Power Plants", Fusion Technology, 39, 1008 (2001).

18. M. L. ABBOTT and A. S. ROOD, "COMIDA: A Radionuclide Food Chain Model for Acute Fallout Deposition," Health Physics, 66, 17 (1994).

19. M. YOUNG and D. CHANIN, "MACCS2 Development and Verification Efforts," SAND-970561C, NRC International MACCS2 User's Group Meeting, September 16-19, 1996, Portoroz, Slovenia, Sandia National Laboratories (1996).

20. S. REYES, L. C. CADWALLADER, J. F. LATKOWSKI, J. GOMEZ DEL RIO, J. SANZ, "Safety Issues of Beryllium Use in IFE Power Plants," presented at the 20th IEEE/NPSS Symposium on Fusion Engineering (SOFE), October 14 - 17, 2003, San Diego, California.

21. L. C. CADWALLADER and J. F. LATKOWSKI, Preliminary Identification of Accident Initiating Events for Inertial Fusion Energy Power Plant Designs, INEEL/EXT-01-01600, Idaho National Engineering and Environmental Laboratory (2003).

22. L. C. CADWALLADER, "Identification and Selection of Initiating Events for Experimental Fusion Facilities", Proceedings of the 13th Symposium on Fusion Engineering, Knoxville, Tennessee, October 1989, IEEE, 1103 (1989).

23. S. REYES, J. F. LATKOWSKI, J. GOMEZ DEL RIO, J. SANZ, "Accident Dose Analysis of the SOMBRERO Inertial Fusion Energy Power Plant Design", Fusion Technology, 39, 941 (2001). 
24. Safety of Magnetic Fusion Facilities - Requirements, DOE-STD-6002-96, U. S. Department of Energy, Washington, D. C. (1996).

25. Safety of Magnetic Fusion Facilities - Guidance, DOE-STD-6003-96, U. S. Department of Energy, Washington, D. C. (1996).

26. L. C. CADWALLADER and D. A. PETTI, "Safety in the Design of Three Burning Plasma Experiments," Fusion Science and Technology, 44, 388 (2003).

27. J. P. SHARPE, D. A. PETTI, and H.-W. BARTELS, "A review of dust in fusion devices: Implications for safety and operational performance," Fusion Engineering and Design, 63-64, 155 (2002).

28. J. RAPP, P. MONIER-GARBET, G. F. MATTHEWS, "Reduction of divertor heat load in JET ELMy H-modes using impurity seeding techniques," Nuclear Fusion, 44, 312 (2004).

29. S. REYES, J. F. LATKOWSKI, J. GOMEZ DEL RIO, J. SANZ, "Accident Consequences Analysis of the HYLIFE-II Inertial Fusion Energy Power Plant Design," Nuclear Instruments and Methods in Physics Research A, 464, 416 (2001).

30. S. REYES, J. F. LATKOWSKI, J. GOMEX DEL RIO, J. SANZ, "Progress in Accident Analysis of the HYLIFE-II Inertial Fusion Energy Power Plant Design", Fusion Technology, 39, 946 (2001).

31. J. F. LATKOWSKI, S. REYES, G. E. BESENBRUCH, D. T. GOODIN, "Preliminary Safety Assessment for an IFE Target Fabrication Facility," Fusion Technology, Vol. 39, 960 (2001).

32. A. RODRIGUEZ et al., "Activation Cross Sections Improvements Needed for IFE Power Reactors Designs," to appear in the Proceedings of the Third International Conference on Inertial Fusion Sciences and Applications, IFSA 2003, 7-12 September 2003, Monterey, California.

33. S. REYES, J. SANZ, J. F. LATKOWSKI, "Use of Clearance Indexes to Assess Waste Disposal Issues for the HYLIFE-II Inertial Fusion Energy Power Plant Design," Fusion Engineering and Design, 6364, 257 (2002).

34. D. A. PETTI, K. A. MCCARTHY, N. P. TAYLOR, C. B. A. FORTY, R. A. FORREST, "Re-evaluation of the use of low activation materials in waste management strategies for fusion," Fusion Engineering and Design, 51-52, 435 (2000).
35. M.C. BILLONE, A.R. RAFFRAY, D.K. SZE, L. ELGUEBALY and the ARIES Team, IFE Structural Materials ARIES Assessment, University of California, San Diego, UCSD-ENG-101 (2002).

36. J. SANZ, O. CABELLOS, S. REYES, J.F. LATKOWSKI, "Effect of activation cross-section uncertainties in selecting steels for the HYLIFE-II chamber to successful waste management," to be presented at the 23rd Symposium on Fusion Technology (SOFT 2004), Venice, Italy, 20-24 September, 2004.

37. S. REYES, J. F. LATKOWSKI, R. P. ABBOTT, W. STEIN, "Simulation of X-Ray Irradiation on Optics and Chamber Wall Materials for Inertial Fusion Energy," to appear in the Proceedings of the Third International Conference on Inertial Fusion Sciences and Applications (IFSA 2003).

38. T. D. MARSHALL, R, J, PAWELKO, R. A. ANDERL, G. R. SMOLIK, B. J. MERRILL, AND R. L. MOORE, Air Chemical Reactivity Measurements of the Carbon Fiber Composite NB31, INEEL/EXT02-00745, Idaho National Engineering and Environmental Laboratory (2002).

39. D. A. PETTI and B. J. MERRILL, "Future US ITER Safety Studies," these proceedings.

40. A. C. BELL, P. BALLANTYNE, C. GORDONT, M. A. WRIGHT, "The safety case for JET D-T operation," Fusion Engineering and Design, 47, 115 (1999).

41. The Tokamak Fusion Test Reactor D-T Modifications and Operations, DOE/EA-0566, US Department of Energy, Washington, DC (1992).

42. M. ZUCCHETTI, R. FORREST, C. FORTY, W. GULDEN, P. ROCCO, S. ROSANVALLON, "Clearance, recycling and disposal of fusion activated material," Fusion Engineering and Design, 54, 635 (2001).

43. J. P. SHARPE, P. W. HUMRICKHOUSE, D. A. PETTI, T. D. MARSHALL, "Dust in ITER: R\&D Needs for Safety Compliance," to be presented at the $23^{\text {rd }}$ Symposium on Fusion Technology (SOFT 2004), Venice, Italy, 20-24 September, 2004. 